\title{
SALUD PÚBLICA: IDEOLOGÍA, PODER, SABER
}

\author{
CÉSAR LIP LICHAM \\ Universidad Peruana Cayetano Heredia
}

Jamás, hombres humanos,
hubo tanto dolor en el pecho, en la solapa, en la cartera,
en el vaso, en la carnicería, en la aritmética!
Jamás tanto cariño doloroso,
jamás tanta cerca arremetió lo lejos,
jamás el fuego nunca
jugó mejor su rol de frío muerto!
jamás, señor ministro de salud, fue la salud
más mortal.
César Vallejo: Los nueve monstruos

Este trabajo está basado en la disertación realizada el 12 de junio de 2017 en el Seminario Avanzado en Salud Pública, que es parte del Programa de Doctorado en Salud Pública de la Facultad de Salud Pública de la Universidad Peruana Cayetano Heredia.

Por alguna razón que aún ignoro, y que, recordando el latinismo ignoramus et ignorabimus (ignoramos e ignoraremos), en este caso ignoro, de repente me encontré un día - mientras buscaba cómo abordar la disertación que se me había solicitado- pensando en París. Creo que tenía que ver con lo que Sócrates propugnaba: los humanos sabemos más de lo que sabemos que sabemos. En esas circunstancias, solo me dejé ir, un tanto desordenadamente, buscando preguntas, más que las respuestas, con el propósito de hilar un discurso para promover la reflexión sobre tres temas: ideología, poder y saber, y algunas de sus implicancias para con la salud pública.

Resulta, por decirlo de alguna forma, complejo abordar un tema como el seña- lado: «Salud Pública: Ideología, Poder y Saber». La complejidad del término $S a$ lud Pública en parte es producto de las diferentes denotaciones y connotaciones que se le ha dado, al menos, durante la época moderna; uso el término moderno referido directamente al proyecto de la Ilustración, cuyo evento emblemático tuvo lugar centralmente en París: la Revolución Francesa.

Durante la Revolución Francesa se formó el tristemente célebre Comité de Salud Pública -Comité de salut public-, que finalmente terminó siendo el órgano con más poder dentro del nuevo Estado, e impuso una época de terror. Pero en este caso no se trataba realmente de la salud pública, ya que la palabra salut remitía a su origen en latín, salvación. Para lograr la salvación se debía crear una república.

Si entendemos como república a una forma de "organización del Estado cuya máxima autoridad es elegida por los ciudadanos o por el Parlamento por un periodo determinado" (Real Academia Española 2014), podemos afirmar que el 
Perú es una nueva república desde 1993 , cuando tras un periodo de gobierno no democrático entra en vigencia la actual constitución política.

En nuestro país, la Constitución Política actual, en su artículo 9. dice que «el Estado determina la política nacional de salud. El Poder Ejecutivo norma y supervisa su aplicación. Es responsable de diseñarla y conducirla en forma plural y descentralizadora para facilitar a todos el acceso equitativo a los servicios de salud"; y en su artículo 11. ${ }^{\circ}$ estipula que «el Estado garantiza el libre acceso a prestaciones de salud y a pensiones, a través de entidades públicas, privadas o mixtas. Supervisa asimismo su eficaz funcionamiento" (Congreso de la República-Perú 2017).

Entonces, se puede entender con claridad que el Estado no garantiza, sino "facilita" el acceso equitativo a los servicios de salud. Es más, en el artículo 2. ${ }^{\circ}$ de la Constitución, que trata sobre los Derechos fundamentales de la persona, no se encuentra el Derecho a la salud.

Reconocer la salud como un derecho debió esperar cerca de diez años, desde que entrara en vigencia la Constitución de 1993, hasta cuando el Tribunal Constitucional, partiendo de la idea de que la salud puede ser entendida como el funcionamiento armónico del organismo tanto físico como psicológico del ser humano, establece que el Derecho a la salud constituye una condición indispensable del desarrollo humano y medio fundamental para alcanzar el bienestar individual y colectivo. Por tanto, deviene en condición necesaria del propio ejercicio del derecho a la vida y, en particular, a la vida digna (Tribunal Constitucional Peruano 2002).

Más allá de si la salud es un derecho humano fundamental en el Perú, lo que queda claro es que las condiciones para el ejercicio de dicho derecho no están dadas, a tenor de múltiples evaluaciones que en los actuales momentos señalan que nos encontramos al borde del colapso del sistema de salud o, más palmariamente, como dice el decano del Colegio Médico del Perú, Miguel Palacios:

El primer punto de la plataforma de la huelga médica es por un aumento del presupuesto al sector salud, eso duele y pone el dedo en la llaga viva y purulenta del sistema político y económico actual. Ya son 82 años recibiendo presupuesto de caridad, aceptando retóricamente que la salud es un derecho humano, pero manteniendo un sistema de salud obsoleto, fragmentado, atomizado, desfinanciado, que no permite brindar a nuestra población un servicio oportuno y de calidad, con antiguos y vanos intentos tecnócratas de reforma sanitaria al margen de los actores sociales y profesionales de la salud, siguiendo la lógica del mercado antes que la lógica de la salud pública (CMP 2017).

¿Se puede "salvar" - del colapso- a la salud pública peruana sin refundar la República Peruana?, o, ¿para tener niveles de salud pública decentes basta con reformar la reforma de la reforma? Cualquier intento de respuesta requiere contestar a la pregunta ¿qué es la salud pública?

\section{ALGUNAS REFLEXIONES SOBRE QUÉ ES LA SALUD PÚBLICA}

\section{Salud pública y complejidad: dialógica individuo-sociedad-especie}

En las preguntas anteriores, el término salud pública refiere a su denotación 
de salud de la población, en esa dicotómica taxonomía de salud individual versus salud colectiva. Clasificación que, en realidad, es del tipo simple.

Desde la complejidad, lo individual y lo colectivo no son más separables que lo celular de lo corporal, la parte y el todo; más aún, cuando el término colectivo incluye la salud en un nivel de análisis cuya unidad es una estructura social -desde un grupo hasta una formación social- $y$, también, la salud de la especie humana; las cuales, igual que la salud individual, no podrán comprenderse ni, por ende, intervenirse con probabilidades de éxito si no se tiene en cuenta el acoplamiento estructural, esto es, el equilibrio dinámico entre las dimensiones física, biológica $\mathrm{y}$ antroposocial y sus entornos.

Vinculado a esto, debe decirse que muchas veces es difícil definir dónde ubicar a la problemática de la salud pública. Por ejemplo, los médicos, que tan frecuentemente acusan a otros profesionales de la salud como intrusos, no tienen reparo para que un médico clínico (un experto en alguna parte -de las múltiples clasificaciones que se pueden hacer- de la salud individual) se inmiscuya ${ }^{1}$ como directivo de instituciones o instancias cuya responsabilidad está directamente relacionada con la salud pública. Lo mismo vale para otras profesiones, incluso para las que no son del campo de las ciencias de la salud, como economistas o abogados. $\mathrm{Y}$ es que los problemas no se encuentran como las piedras en los caminos, los árboles en el campo o los peces en el mar. Los problemas de salud pública resultan definidos por la diferencia entre la norma y la naturaleza: las normas son nuestras, pero la naturaleza no, como cantaba Atahualpa Yupanqui:

Las penas y las vaquitas se van por la misma senda, las penas son de nosotros, las vaquitas son ajenas.

\section{Salud pública: práctica social compleja}

Desde una perspectiva compleja, entonces, la salud pública en su connotación como problemática reclama a la salud pública en su connotación como acción o conjunto de acciones, como intervención socialmente organizada.

Mas esta acción, en primer lugar, no resulta ser del tipo Yo (sujeto) actúo sobre la naturaleza (objeto), porque Yo también es parte de la naturaleza, un sujeto-objeto como tan parte de la naturaleza es un grupo social, la cultura de un pueblo (Elias 1997) o la humanidad de la humanidad entera misma (Morin 2003).

Hoy en día, nos movemos en un marco intelectual centrado en dicotomías conceptuales como «naturaleza y sociedad», «naturaleza y cultura», «objeto y sujeto», «materia y espíritu», o hasta "tiempo físico y tiempo vivido", etc. Aunque algunos de estos pares de contrarios nos han sido transmitidos de tiempos pasados, reflejan, sin embargo, muy fuertemente, en su concepción actual dominante, las diferencias de evolución de nuestro saber y la división de la búsqueda del saber en especialidades académicas desligadas (Elias 1997: 88).

1 Entrometerse, tomar parte en un asunto o negocio, especialmente cuando no hay razón o autoridad para ello (RAE 2014). 
Por tanto, es necesario concebir a la salud pública como campo de conocimiento y ámbito de acción, remarcando la $y$ en su carácter de conjunción copulativa, pero sin que resulte una adición, como suele tomarse en las construcciones académicas y en los espacios socioburocráticos, sino como los elementos complementarios de un todo que pueden comprenderse como una práctica social. Práctica social que es un "todo", cuyas partes -conocimiento y acción- la constituyen dialógicamente, jugando papeles, concurrentemente, antagónicos y complementarios ${ }^{2}$.

Entonces, la salud pública como problemática y la salud pública como actuación constituyen un sistema social, por tanto, están interrelacionadas. Lo que desde un paradigma científico mecanicista se ve como dos piezas separadas que se yuxtaponen y que pueden ser abordadas reduccionistamente (piénsese, como ejemplo, en la epidemiología y la administración de salud newtonianas-cartesianas), desde el paradigma de la complejidad se observa como un nuevo sistema: una emergencia de la interrelación de sus partes, sistema cuyos elementos son, a la vez, sus procesos y productos. Los procesos de interacción entre problemática y acción son de variados tipos de acciones: interacciones, retroacciones, reacciones, transacciones.

La novedad, la emergencia, es una de las principales características de los sistemas complejos (Morin 1977), que exige entender el todo y sus partes conjuntamente. Como dijera Pascal (2004), claro, desde París: "...considero imposible conocer

las partes sin conocer el todo, y también conocer el todo sin conocer particularmente las partes."

Podemos parafrasear a Pascal y decir:

...considero imposible conocer la problemática sanitaria

y la acción organizada en salud sin conocerla como práctica social, y también conocer la salud pública como práctica social sin conocer particularmente la problemática sanitaria y la acción organizada en salud.

Es necesario estar alertas para no reificar, como suele ocurrir en la vida cotidiana (Watzlawick 1979), y tomar el concepto sistema como una cosa. En este caso, el término sistema refiere a: 1) un conjunto de procesos de intervención socialmente organizada y 2) un conjunto de procesos para conocer qué intervenciones realizar para mejorar la salud de la población. Esta conjunción de procesos es conceptualmente central para definir a la salud pública como una práctica social.

En cada situación, la evolución de las interrelaciones entre estos dos conjuntos de procesos y de las interrelaciones entre los elementos y el todo que se van configurando lleva a la emergencia de un sistema de salud pública ${ }^{3}$ particular; bajo esta perspectiva, los sistemas de salud pública son autopoiéticos ${ }^{4}$, autoformaciones. Este es el otro criterio que se requiere para calificar a un fenómeno como complejo.

2 Sobre el principio dialógico puede consultarse las diversas obras de Edgar Morin dedicadas al pensamiento complejo.

3 No confundir con la institución que se suele denominar así.

4. Para ampliar sobre el concepto de autopoiesis puede consultarse Maturana \& Varela, De Máquinas y Seres

Vivos. Autopoiesis: la organización de lo vivo (1994) 
Resumiendo, una declaración, una definición: la Salud Pública es una práctica social compleja, configurada por las interrelaciones entre los procesos de la vida y la salud de las personas y los procesos mediante los cuales los agentes sociales actúan organizadamente sobre ellos, siendo ambos tipos de procesos socialmente determinados. Hasta aquí, algunas ideas sobre la salud pública y la complejidad y, además, una definición descriptiva. Sobre esta, algunas reflexiones enseguida.

\section{La salud pública como práctica}

Todo sistema de ideas es simultáneamente abierto y cerrado, esto es, dejan entrar nuevas ideas y, a la vez, buscan defenderse -como sistema total y coherente- de las refutaciones que puedan derivar del mundo exterior. Usando el concepto de tipos ideales, desarrollado por Max Weber, se puede dividir a los sistemas de ideas en dos tipos. Uno de ellos de tipo abierto, para señalar a los sistemas en los cuales la apertura precede a la clausura, y otro de tipo cerrado, que contiene a los sistemas de ideas donde la clausura precede a la apertura. A los sistemas del primer tipo se le llaman teorías, mientras que a los otros se les denomina doctrinas (Morin 1998: 133). Globalmente, la ciencia está compuesta por sistemas abiertos de ideas, y las religiones por sistemas cerrados de ideas.

En el ámbito académico es común entender que las actividades se dividen en dos tipos: teóricas y prácticas. Por un lado, lo teórico refiere en este caso a un sistema de ideas abierto. Por otro lado, se suele denotar a la práctica como al ejercicio de un modo de hacer las cosas de acuerdo a lo que indica la teoría; es la acepción que aparece como la correspondiente, dentro de las trece definiciones que del término práctica se puede encontrar en el diccionario de la RAE.

Frente la definición de la salud pública como una práctica, se podría entender que se la está conceptuando como «Actuar según lo prescrito en las teorías de la salud pública", enunciado que en parte es correcto, pero que la reduce. Para evitar dicha reducción se necesita avanzar más sobre el «actuar» que respecto a «según lo prescrito en las teorías...».

Gehlen (1993) postula que el hombre puede ser definido esencialmente como un ser que actúa; pero que actúa desde su libertad de elegir, agrega Savater (2003). Esta condición de actividad de los humanos fue clasificada por Aristóteles en dos tipos: praxis (actuar por el solo gusto de hacerlo, esto es, sin buscar un fin) y poiésis (actuar para crear, producir, algo), siendo lo distintivo de los humanos no la creación de objetos o instrumentos, sino la creación de humanidad.

La praxis es autopoiética: la principal industria del hombre es inventarse y darse forma a sí mismo (Savater 2003: 25).

Ampliando, la teoría de la acción (praxiología) considera que cuando hablamos de acción en general referimos a lo que la desencadena y de cómo las acciones concurrentes de diferentes individuos se combinan para producir hechos sociales (Bunge 2009: 77).

Entonces, definir a la salud pública como una práctica, una praxis autopoiética, enfoca el carácter esencial de acción colectiva que las personas llevan adelante con el fin de mejorar su situación de salud y aquello que la determina. 


\section{La salud pública y «lo social»}

Los humanos aparecemos como individuos, grupos sociales o especie, de acuerdo al observador. Por ejemplo, cuando la mirada médica clínica se fija en el individuo, la sociedad y la especie suelen desaparecer de la mente del observador, y bajo una mirada sociológica o antropológica el individuo tiende a desvanecerse (Morin 2003).

La mirada de la salud pública, desde la complejidad, asienta en buscar conocer y transformar la salud de la trinidad individuo-sociedad-especie:

Lo humano se define en primer lugar como trinidad individuo-sociedad-especie: el individuo es un término de esta trinidad.Cada uno de estos términos contiene a los otros. No sólo los individuos están en la especie, la especie está en los individuos; no sólo los individuos están en la sociedad, la sociedad está en el interior de los individuos imprimiéndoles su cultura desde su nacimiento (Morin 2003).

Las relaciones entre estos tres términos son de tipo dialógico, esto es, repitiendo, concurrentes, complementarias y antagónicas; y aunque unos dependan de los otros -inclusive cada uno de ellos es fin y medio de los otros-, no son reductibles. Por tanto, al calificar a la salud pública como práctica social no se intenta aislarla de sus complementos, individuo y especie, ni que se desvanezca en ellos.

En términos de organización, lo social remite a un nivel superior al de lo individual. En consonancia con lo presentado antes, las agrupaciones sociales tienen atributos que han emergido en su autopoiésis, atributos que no tienen los individuos que la conforman, pero también son algo menos que la suma de sus partes, ya que algunos de los atributos de los individuos no son transferibles a la agrupación social que integra.

Una agrupación social dispone de capacidades y cualidades de organización y producción de un nivel cualitativamente superior a las de cualquiera de sus miembros individuales. En ese sentido, la capacidad de concebir, diseñar e implementar acciones de salud pública que tienen las agrupaciones sociales es cualitativamente superior a la que tienen individualmente sus miembros, sin importar cuán importante sea el puesto que ocupe en el ordenamiento jerárquico de dicha agrupación.

Esto, evidentemente, admite varios niveles de agrupación. En el espacio del Estado-nación suele encontrase personas que, encandiladas con el poder del puesto burocrático que ocupan, creen que su capacidad organizativa individual o institucional es superior a la de cualquier otro nivel de organización social. Ese deficiente entendimiento de los sistemas complejos se traduce en la creencia y los consecuentes comportamientos del mito de la «hormiga reina» (Johnson 2003).

Entonces, si bien una agrupación social tiene atributos de los cuales sus miembros individuales carecen, también resulta ser una unidad que es menos que la suma de los atributos de los miembros que la componen. Por ejemplo, una organización, si bien utiliza el pensamiento y la conciencia de los miembros que gobierna, no dispone de autorreflexión, puesto que esta es una capacidad de la conciencia individual. Respecto a la salud pública, la ausencia de autorreflexión se reemplaza con mecanismos como la evaluación, que más allá de los propósitos técnicos está fuertemente influida por los 
diversos intereses de los agentes sociales, entre ellos los de tipo económico, cultural, político e ideológico (sobre lo que se trata después).

Algunas de las ideas presentadas son parte de aquellas que están en la base de la conceptualización que hace la OPS/OMS de la salud pública como práctica social:

El concepto de salud pública en el que se basa la definición de las FESP es el de la intervención colectiva, tanto del Estado como de la sociedad civil, orientada a proteger y mejorar la salud de las personas. Es una definición que va más allá de los servicios de salud no personales o de las intervenciones de carácter comunitario dirigidas a la población, e incluye también la responsabilidad de asegurar el acceso a los servicios y la calidad de la atención de la salud. Abarca, asimismo, las acciones de fomento de la salud y de desarrollo del personal que trabaja en la salud pública. Así pues, no se refiere a la salud pública como una disciplina académica, sino como una práctica social de naturaleza interdisciplinaria. Se trata, por otro lado, de una conceptualización que va más allá de la noción de bienes públicos con externalidades positivas para la salud, ya que comprende bienes semiprivados o privados cuyas dimensiones hacen que su repercusión sobre la salud colectiva sea un factor importante (OPS/OMS 2002).

En resumen, la salud pública es una práctica social porque está constituida por acciones colectivas de agentes sociales -generalizando, de la sociedad organizada-, porque consiste en enfrentar problemas de salud de, y con, los grupos sociales, y porque usa como concepto-peana la determinación social de la vida y la salud ${ }^{5}$ (Breilh 2010). La salud pública como práctica social se configura como sistema, en la interrelación entre procesos de acción y procesos de pensamiento sobre situaciones de salud de una población, y constituye un campo de poder y un campo de saber ${ }^{6}$.

\section{SALUD PÚBLICA: CAMPO DE PODER, CAMPO INTELECTUAL}

La trinidad individuo-sociedad-especie se concreta en espacios que pueden comprenderse usando la noción de campo. Entonces, volvemos a París para tomar de Pierre Bourdieu la noción de campo, que es aplicable en la definición de la salud pública como «campo de acción y de conocimiento»:

Un campo es un sistema competitivo de las relaciones sociales que funciona según su propia lógica interna, compuesta de instituciones o individuos que compiten por lo mismo. Lo que generalmente está en juego en este campo es el logro del máximo dominio en su seno -un dominio que permite a quienes lo consiguen otorgar legitimidad a otros participantes o retirarla-. Conseguir este dominio supone amasar la máxima cantidad de un tipo particular de "capital simbólico" apropiado al campo; y para que este poder se vuelva "legítimo" debe dejar de ser reconocido como lo que es. Un poder que se avala de manera tácita en vez de explícita es aquel que ha conseguido legitimarse a sí mismo (Eagleton 1977: 202).

5 Este último punto será algo más desarrollado al tratar sobre Salud Pública e Ideología.

6 Nótese que estamos utilizando una definición de tipo relacional y no una sustancialista. Sobre estos tipos de definición puede consultarse Bourdieu (2007) 
La salud pública como práctica social tiene lugar en el mundo real $^{7}$, constituyéndose en un campo social, o como señala Bourdieu, en:

[...] un espacio estructurado de posiciones (o de puestos) cuyas propiedades dependen de su posición en dichos espacios y pueden analizarse en forma independiente de las características de sus ocupantes (en parte determinados por ellas) [...].

Un campo - podría tratarse de un campo científico- se define, entre otras formas, definiendo aquello que está en juego y los intereses específicos, que son irreductibles a lo que se encuentra en juego en otros campos o a sus intereses propios (no será posible atraer a un filósofo con lo que es motivo de disputa entre geógrafos) y que no percibirá alguien que no haya sido construido para entrar en ese campo[...]. Para que funcione un campo, es necesario que haya algo en juego y gente dispuesta a jugar, que esté dotada de los habitus que implican el conocimiento y reconocimiento de las leyes inmanentes al juego, de lo que está en juego, etcétera (Bourdieu 2002: 119).

Antes de seguir, es importante explicitar que el habitus de salubrista es a la vez un "oficio", un cúmulo de técnicas, de referencias, un conjunto de "creencias" que lo habilitan a jugar en el campo de la salud pública (adaptado de Bourdieu 2002: 120).

Algunas de las preguntas a las que invita la aplicación de la noción de campo a la salud pública son estas: ¿qué es lo que está en juego en el campo de la salud pública?, ¿cuáles son las reglas de juego?, ¿quiénes son los jugadores?, ¿cuáles son sus intereses específicos?, ¿los jugadores están dotados con los habitus que implican el conocimiento y reconocimiento de las leyes inmanentes al juego, de lo que está en juego, etcétera?

Esas preguntas mayormente no tienen respuestas simples, pero las respuestas resultan necesarias para los agentes sociales: podrían estar jugando el juego equivocado y adquiriendo habitus no correspondientes al campo.

Para tentar respuestas a las preguntas anteriores es necesario tener en cuenta otra ley general de la noción de campo:

La estructura del campo es un estado de la relación de fuerzas entre los agentes y las instituciones que intervienen en la lucha o, si ustedes prefieren, de la distribución del capital especifico que ha sido acumulado durante luchas anteriores y que orientan las estrategias ulteriores. Esta misma estructura, que se encuentra en la base de las estrategias dirigidas a transformarla, siempre está en juego: las luchas que ocurren en el campo ponen en acción al monopolio de la violencia legítima (autoridad especifica) que es característico del campo considerado, esto es, en definitiva, la conservación o subversión de la estructura de la distribución del capital específico (Bourdieu 2002: 120,121).

En este marco, el concepto capital especifico refiere a la idea de que el valor del capital está relacionado con un campo determinado. Es decir que los capitales espe-

7 Esto incluye a los tres mundos, sobre lo cual se trata después. 
cíficos de un campo no son -en general, difícilmente lo son- transferibles a otro campo. El capital específico es el fundamento del poder o de la autoridad específica característica de un campo; de allí la importancia de la acumulación de capital específico, que resultará en determinante de las estrategias de los jugadores.

Las preguntas vuelven a surgir casi directamente: ¿cuál es el capital específico en el campo de la salud pública o cuáles son sus componentes?, ¿qué agentes o actores sociales tienen mayor capital específico sanitario, globalmente o por tipo de componente, como cuánto y cómo resulta el balance de poder?, ¿hay un monopolio del capital específico global, o de algunos de sus componentes?

Un ejemplo: la pandemia de la gripe AH1N1, la gripe porcícola (Breilh 2009), que suele ser denominada "porcina", declarada por la OMS el 2009 que llegó hasta la fase 5. ¿Cuál fue el juego?, ¿cuáles fueron las reglas del juego?, ¿quiénes fueron los actores y cuáles sus intereses?, ¿qué capitales específicos (cultural, político, administrativo, técnico, científico, literario, económico, etc.) se movilizaron?, ¿cuál de ellos devino en capital simbólico?, ¿cuál fue el papel de la salud pública, como conocimiento y como acción?, ¿la salud pública usó su conocimiento acumulado para actuar adecuadamente frente al problema planteado o cierto conocimiento de la salud pública -la epidemiología funcionalista- utilizado para otros objetivos que no eran proteger y mejorar la salud de la población?

Entonces, ¿nos sirvió el enfoque de los determinantes sociales de la salud de la OMS (DSS) (OMS 2008)?, ¿qué dice sobre el asunto la salud pública, basada en la determinación social de la vida y la sa- lud (DSVyS) (Breilh 2010), de la corriente de la medicina social latinoamericana y su epidemiología crítica (Henao-Kaffure 2010)? Y, evidentemente, la pregunta de fondo, ¿qué aprendió el órgano rector del sector salud del Perú?

Es imprescindible pensar otros problemas de salud pública bajo la interrogante ¿resulta el caso de la pandemia de la gripe AH1N1 un caso aislado en que el capital económico resulta ser el capital simbólico? Ese tipo de capital que Bourdieu (2002) cataloga como «el fundamento del poder o de la autoridad específica característica de un campo, [...] el gran determinante de las estrategias de los jugadores».

Dentro del Perú, ¿̨cuál capital específico tiene el poder en el campo de la salud y cuáles teorías del campo de la salud pública le asisten? Respecto a las estrategias frente a problemas de salud pública, por ejemplo, las transmitidas por el anopheles y la anemia, ¿qué capitales específicos están, realmente, movilizando?, ¿cuánto del saber de la salud pública -capital científico y capital técnico acumulado- se está utilizando?, ¿las estrategias basadas en la aplicación de pesticidas y reparto de fármacos antiparasitarios son las adecuadas, tomando en cuenta los DSS o la DSVyS?, jestamos ante una mebendazolización del problema de alta prevalencia de anemia?

\section{SALUD PÚBLICA Y SABER}

Sin duda, imaginar, o incluso afirmar, que conocer el oficio (estar dotado con los habitus) de la salud pública resulta un importante capital específico, capital intelectual, mucho mejor si es un saber formalizado. Pero nuevamente surgen las mismas preguntas, ya que solo es deslizarse hacia la otra parte del campo, la parte del conocer, 
esto es, estamos pasando del actuar al conocer. Es, entonces, obligatorio enfrentar las mismas preguntas particularizadas para el conocer: ¿cuál es el juego en la salud pública como campo de conocimiento?, ¿cuáles son las reglas del juego?; así como, ¿quiénes son los jugadores?, ¿cuáles los intereses que defienden?, ¿cuánto tienen como capital específico?, ¿cuáles son sus estrategias? El asunto no es tan simple; aquí también es necesario un abordaje desde la perspectiva de la complejidad, que sobrepasa largamente los límites de esta presentación. Sin embargo, es necesario tratar, al menos escuetamente, sobre algunos de los asuntos a los que llama el conocer.

El primero, un aspecto general en la teoría de la acción. Hay un asunto radical que suele llevar a confusión: considerar que actuar y pensar (hacer y conocer) son actividades diferentes, este error resulta de definir la acción exclusivamente sobre la base del operar del cuerpo respecto a su entorno. Es importante comprender que el pensar es el hacer del pensador.

Así, pensar es actuar en el ámbito del pensamiento, caminar es actuar en el ámbito del caminar, reflexionar es actuar en el ámbito de la reflexión, hablar es actuar en el ámbito del habla, golpear es actuar en el ámbito del golpear... explicar científicamente es actuar en el ámbito de la explicación científica (Maturana 1995).

En ese sentido, el trabajo de generación, gestión y transmisión del conocimiento en salud pública es parte de ella. Enseñar salud pública e investigar en salud pública es parte de ella como práctica social. Es necesario dejar de verla solo analíticamente, despedazarla como objeto de trabajo, como cuando afirmamos que la salud pública tiene dos partes. Una, el estudio de las condiciones de salud de la población; la otra, la respuesta social organizada para mejorar esas condiciones.

En corto, la salud pública como práctica social incluye la acción y el conocimiento, en cuya interrelación se constituyen como una unidad dialógica. Actuar y pensar en salud pública resultan los elementos que se interrelacionan en lo que antes llamamos el sistema de salud pública, un sistema que se concreta como un campo social, en el cual sus elementos, acción y conocimiento, resultan complementarios, antagónicos y concurrentes, cuyas interrelaciones -acciones, reacciones, retroacciones, transacciones-, constituyen diacrónicamente los procesos de su configuración, y cuyo estado puede evaluarse como un campo de poder. Todo ello puede verse desde una nueva aproximación epistemológica, la que implica trabajar escapando a la clásica definición que distingue el objeto a conocer y el sujeto cognoscente, lo observado y el observador, como proponen Von Foerster (1998) y Morin (2002), entre otros, desde una postura constructivista radical.

Conceptuar cabalmente la salud pública como una práctica social que tiene lugar en el mundo real, requiere entender la idea de los tres mundos propuesta por Popper (1978):

- Mundo 1: los cuerpos físicos. Por ejemplo, las vacunas, los cuerpos, el equipamiento médico, los alimentos, los relaves mineros, pero también las estrellas, las plantas y los animales, así como la radiación, y otras formas de energía física.

- Mundo 2: los estados o procesos mentales o psicológicos, o mundo de la experiencia subjetiva. Están allí los pensamientos, los sentimientos, las observaciones, las percep- 
ciones, las decisiones. Se distinguen dos submundos: consciente e inconsciente.

- Mundo 3: los productos de la mente humana, tales como el lenguaje, las historias, los mitos -incluyendo los religiosos-, las conjeturas o teorías científicas y construcciones matemáticas, las canciones y las sinfonías, pinturas y esculturas, etc. Ejemplos del mundo 3 son la Ley General de Salud, El Gran Escape de Angus Deaton, la Teoría epigenética de Barker.

En la salud pública como en otros ámbitos, muchos de los objetos del mundo 3 pertenecen al mismo tiempo al mundo 1 , el de los objetos físicos. Por ejemplo, un libro sobre estrategias sanitarias es un objeto físico y una creación (abstracciones) de la mente del autor. Entonces, cuando se dice que las ideas que se encarnan, plasman o realizan, es que también quedan en alguna forma comprendidas en objetos concretos del mundo 1 .

Los objetos del mundo 3 son reales, en el sentido que no pertenecen al mundo de la ficción o de las cosas imaginarias. $\mathrm{Y}$ pueden tener un efecto causal sobre nosotros, sobre nuestras experiencias del mundo 2, y sobre nuestros cerebros, es decir, sobre nuestros cuerpos materiales (mundo 1).

En resumen, la salud pública no se trata de una práctica empirista ni una teorización trivial ni tampoco una actividad diletante -en el sentido usado por Weber (1996) - propia de aficionados. La salud pública, en la cual mutatis mutandi incluimos la salud internacional y la salud global, es una práctica social que se au- toforma como un sistema real, por la dinámica interactiva de sus elementos que pertenecen a los mundos 1, 2 y 3 de la propuesta popperiana.

No siendo de diletantes, en el marco de lo que hasta acá hemos desarrollado en este texto, la salud pública requiere de profesionales; por tanto, se constituye también como una disciplina científica que en su práctica permite a quienes la ejercen el desarrollo de los habitus correspondientes al oficio de salubrista.

En los últimos ańos, cerca de un cuarto de siglo ya, se ha trabajado al menos en Latinoamérica extensamente con los aportes de la llamada Nueva salud pública (Frenk 1991), en la cual se divide la trinidad individuo-sociedad-especie, dejando la salud individual como objeto de trabajo de la medicina, enfermería, obstetricia, psicología, etc. clínicas $^{8}$, y tomando la salud colectiva como su objeto de trabajo ${ }^{9}$, habiéndose en los últimos tiempos expandido para abordar la salud internacional y la salud global.

La salud internacional alcanza los problemas de salud que afectan a todos los países; trabaja con un enfoque que toma en cuenta la diversidad entre, y al interior de, los países en desarrollo, que lleva adelante medidas bilaterales y multilaterales, con un enfoque de interdependencia en las actividades de cooperación en enseñanza, investigación y servicios de salud; enfatizando en la transición epidemiológica y en la transición de los servicios de salud. La salud global se sustenta en tres dinámicas: a) la

8 Se propone, en realidad, tres niveles de análisis: subindividual, individual y poblacional, y como conjunto de acciones: biomedicina, clínica y salud pública, respectivamente.

9 El tema de la especie no aparece en el documento. 
transferencia de riesgos y oportunidades, b) la multiplicidad de actores sociales en salud, y c) la presencia del tema de salud en la agenda del desarrollo económico, la seguridad global y la democracia (Frenk \& Gómez-Dantés 2007).

La lógica en las tres instancias aparece como distinta, pero no tanto por la ampliación de la población objeto de trabajo, ni por el aumento del número de actores o su incorporación en la agenda de organismos multinacionales, sino porque fundamentalmente los actores son otros, y podría comprenderse dentro de la tendencia de cambiar el modelo de las relaciones internacionales, pasando del modelo realista (Realpolitik) sancionado al firmarse la paz en Wesphalia al modelo cosmopolita o de la Carta de las Naciones Unidas. Esto ya se ubica más en el tema de la ideología y la salud pública y el poder, sobre lo que se tratará más adelante.

Volviendo a la salud pública en el campo académico-profesional, aparece con claridad que un abordaje unidisciplinario no podría ocuparse de la tarea de entender la trinidad individuo-sociedad-especie. Para convencerse de ello solo hay que dar una mirada a los principales saberes especializados de salud pública necesarios, con lo cual se puede abordar dicha tarea con probabilidades de éxito:

- un saber de qué se necesita y un saber de qué hay que hacer,

- un saber de quién necesita qué y de quién hace qué,

- un saber de quién puede saber y quién puede hacer.

- un saber de cómo hacer lo que se necesita y de cómo hacer para saber lo que se necesita saber y saber lo que se necesita hacer,
Todos esos saberes conteniendo, a su vez, saberes de los cuándos y los dóndes, y sobre todo, saberes de los paraqués y los porqués.

De lo anterior, la salud pública aparece como un tejido multiforme de múltiples colores, sabores, olores, sabores y texturas, en cuya urdiembre intervienen hilos igualmente multiformes, de múltiples colores, etc. Así de complejo y limitando la metáfora solo a lo sensual, pero si se extiende la metáfora fenomenológica, y hermenéuticamente, y se incorporan otras variables, como velocidad, severidad, profundidad, rigurosidad, razonabilidad, etc., se tendrá una representación de la salud pública como un objeto de muy alta complejidad. Sin duda, la metáfora puede seguir extendiéndose, imbricando anidadamente, interactuando, retroactuando, transaccionando en variados niveles y dimensiones, vía metametáforas hacia la hipercomplejidad.

Sin embargo, como dicen Bateson y Bateson, no debemos confundir el mapa con el territorio:

Una descripción nunca puede parecerse a la cosa descrita y sobre todo la descripción nunca puede ser la cosa descrita. La única verdad que se acercará al nivel absoluto es la verdad que la cosa misma podría suministrar si pudiéramos acercarnos tanto a ella (cosa que desgraciadamente nunca podemos, como hace ya tanto tiempo que lo indicó Immanuel Kant). De la cosa misma, el Ding as sich, sólo podemos obtener información de una de sus pocas diferenciaciones inmanentes y susceptibles de ser recogidas por nuestros órganos sensoriales y los instrumentos científicos (Bateson \& Bateson 1987: 152). 
En ese sentido, debemos entender que la salud pública como saber especializado o disciplina resulta ser el mapa y las situaciones sanitarias los "territorios». Y que, por muy cercana que sea la aproximación a las estructuras sanitarias -caso la salud pública basada en evidencias o cualquier otro conocimiento- sigue siendo un mapa. Claro que hay quienes sostienen que «solo existen los mapas», pero ese tema sobrepasa con creces las intenciones de esta presentación. Lo que se requiere en la práctica sanitaria no son siempre mapas hipercomplejos, sino mapas del nivel pertinente que permita la toma de decisiones según el grado de estructuración del problema sanitario. Esto es, globalmente, «mapas» bien estructurados para problemas bien estructurados, «mapas» cuasiestructurados para problemas cuasiestructurados, y «mapas» complejos para los problemas no estructurados.

Desde la simplicidad, la salud pública, también, puede entenderse como una disciplina académica, cuyo objeto de trabajo es la salud de la población, la que estudia utilizando el método inductivo-deductivo. Pero es una disciplina que se sirve de otras, como la biología, la medicina, la psicología, la sociología, la historia, la antropología, la estadística, la economía, la administración. Por esta última característica, hace unas décadas algunos la definían como una ciencia de segundo nivel, entendida como un cuerpo de conocimientos multi o pluridisciplinario.

La salud pública como práctica social ha sido conceptualizada como una interdisciplina $^{10}$, lo cual significa un avance respecto a su consideración como multidisciplinaria, pero sigue siendo una calificación restrictiva.

La interdisciplinariedad ${ }^{11}$ refiere a la transferencia de métodos de una disciplina a otra. Y, de ella, se distingue tres grados:

a. un grado de aplicación. Por ejemplo, los métodos de la inmunología transferidos a la salud pública originaron la intervención mediante la inmunoprevención); b. un grado epistemológico. Por ejemplo, la transferencia de los métodos cuantitativos de la estadística y de los estudios cualitativos de la antropología han generado importantes avances en la epistemología de la salud pública;

c. un grado de concepción de nuevas disciplinas. Por ejemplo, la transferencia de los métodos de las ciencias sociales a la salud pública «tradicional» produjo la medicina social; de la medicina basada en evidencias a la salud pública basada en evidencias.

Definida así, la interdisciplinariedad puede considerarse como atributo de la salud pública. Sin embargo, el objeto de estudio sigue resultando un ente de la(s) disciplina(s).

La salud pública como práctica social va más allá de las disciplinas y a través de ellas; es transdisciplinaria, entendida esta a partir de la idea central siguiente:

La clave de la bóveda de la transdisciplinariedad reside en la unificación semántica y operativa de las acepcio-

10 Ver cita OPS/OMS en el apartado sobre La salud pública y "lo social”.

11 Puede consultarse Pérez, Nuria y Setién, Emilio. La interdisciplinariedad y la transdisciplinariedad en las ciencias: una mirada a la teoría bibliológico-informativa, en http://bvs.sld.cu/revistas/aci/vol18_4_08/aci31008.htm 
nes a través y más allá de las disciplinas. Ello presupone una racionalidad abierta, a través de una nueva mirada sobre la relatividad de las nociones de «definición» y «objetividad» (Primer Congreso Mundial de Transdisciplinariedad, 1994).

Cuando se concibe a la salud pública como una práctica social transdisciplinaria no se niega su disciplinariedad, multidisciplinariedad, ni interdisciplinariedad, sino que se las asume y complementa. La salud pública en tanto saber es transdisciplinario (va más allá y a través ${ }^{12} \mathrm{de}$ las disciplinas), multinivel (disciplina/ multidisciplina/interdisciplina; nacional/ internacional/global), multidimensional (físico/biológico/mental; social/cultural/ económico/político-legal/científico-tecnológico/ideológico) y multirreferencial (individuo/sociedad/especie; vida/salud/ enfermedad; ausencia de centro de referencia universal), histórica y temporalmente contextualizado.

Dos asuntos importantes adicionales. El primero, comprender a la salud pública como saber requiere seguir el avance en la psicología cognitiva, incluyendo el cuestionamiento de la categoría representación, que le es central -como hace Varela en su libro Conocer, donde propone el concepto de enacción, avanzando a partir de los aportes de la fenomenología de la percepción: Husserl, Heidegger, Merlean-Ponty, Foucault (Varela 2005). El segundo asunto es no perder de vista que la salud pública como campo de conocimiento o campo científico tiene también las características de todo campo social: es un campo de poder, un espacio de lucha entre actores sociales.

\section{SALUD PÚBLICA E IDEOLOGÍA}

Si cada uno de los temas anteriores (salud pública, saber, poder) abre mundos enteros a la reflexión sobre la base de la revisión de algunos trabajos importantes de tantos aportes que se ha ido produciendo, esencialmente en el último medio siglo, el vocablo ideología provoca no solo a la imaginación científica, sino también a las emociones y sentimientos. El rango de posiciones sobre la ideología como tema a tratar es tan amplio que va desde que es algo sobre lo que ya no vale la pena hablar, dado que su muerte ha sido decretada, hasta que no puede tratarse seriamente ningún tema social sin tener en cuenta los aspectos ideológicos implicados.

Enseguida, en el límite marcado para esta presentación, se aborda el tema siempre como una reflexión en búsqueda de sus implicancias en la salud pública.

Inicialmente, es necesario decir que respecto a la noción de ideología no se ha logrado una definición universalmente aceptada:

Nadie ha sugerido todavía una adecuada definición de ideología [...]. Esto no se debe a que los entendidos en esta materia destaquen por una baja inteligencia sino porque el término «ideología» tiene un amplio abanico de significados útiles y no todos compatibles entre sí [...]. La palabra «ideología», se podría decir, es un texto, enteramente tejido con un material de diferentes filamentos conceptuales; está formado por historias totalmente divergentes, y probablemente es más importante

12 En sentido duplo: las atraviesa y hace la travesía con ellas. 
valorar lo que hay de valioso o lo que pueda descartarse de cada uno de estos linajes que combinarlos a la fuerza en una gran teoría global" (Eagleton 1997: 19).

Algunas definiciones de las recopiladas por Eagleton: a) el proceso de producción de significados, signos y valores en la vida cotidiana; b) conjunto de ideas característico de un grupo o clase social; c) ideas que permiten legitimar un poder político dominante; d) ideas falsas que contribuyen a legitimar un poder político dominante; e) comunicación sistemáticamente deformada; f) aquello que facilita una toma de posición ante un tema; g) tipos de pensamiento motivados por intereses sociales; $\mathrm{h}$ ) pensamiento de la identidad; i) ilusión socialmente necesaria; j) unión del discurso y el poder; k) medio por el que los agentes sociales dan sentido a su mundo, de manera consciente; l) conjunto de creencias orientadas a la acción; $\mathrm{m}$ ) confusión de la realidad fenoménica y lingüística; $n$ ) cierre semiótico; ñ) medio indispensable en el que las personas expresan en su vida sus relaciones en una estructura social; o) proceso por el cual la vida social se convierte en una realidad natural.

En el conjunto de definiciones anteriores hay similitudes y diferencias, un gran rango de amplitud, alusiones epistemológicas, neutras, falsas, ambiguas, etc.

En general, nuevamente utilizando el concepto de tipos ideales, hay dos tradiciones del término «ideología»:

1. Tradición epistemológica ${ }^{13}$, mayormente desarrollada por pensadores inte- resados por las ideas de conocimiento verdadero o falso, por la noción de ideología como ilusión, distorsión y mistificación.

2. Tradición sociológica, interesada más por la función de las ideas dentro de la vida social que por su realidad o irrealidad.

En el lenguaje común, el término ideología es muy frecuentemente utilizado, con connotaciones diversas. Por ejemplo, una nota periodística recientemente publicada dice lo siguiente:

La parlamentaria fujimorista Cecilia Chacón se refirió a la ministra de Justicia Marisol Pérez Tello y consideró que ella "tiene un sesgo ideológico" debido a su posición sobre la posibilidad de indulto al expresidente Alberto Fujimori (La República.pe).

Probablemente, en este contexto, "sesgo ideológico" se haya usado como la tendencia a juzgar un tema particular desde un armazón rígido o mediante ideas preconcebidas que deforman o ya permiten ver cuál es su juicio, todo ello bajo la idea de que hay una forma neutral y otra distorsionada de considerar un determinado tema particular. Bajo esta concepción, la ideología se toma como una mirada estereotipada o parcializada, negativa, que incluso puede llegar al fanatismo. La ideología como algo negativo, peyorativo.

Como marco, enunciamos que no puede identificarse algo, ni tenerse juicio alguno sobre ello, sin tener presuposiciones, o sea, nuestro pensamiento siempre es ideológico, entonces, "sesgo ideológico” no es una expresión válida.

13 Se refiere a la epistemología como teoría del conocimiento (a la usanza alnglosajona) y no como filosofía de la ciencia. 
Entre las definiciones anotadas anteriormente se puede encontrar directas referencias a lo siguiente:

- El poder: conjunto de ideas para legitimar el dominio de un grupo sobre otro/unión del discurso y el poder; pero ¿el conjunto de ideas de los que luchan para obtener el poder no es ideología? Quienes dominan en el campo de la salud pública tienen una ideología, y los que quieren cambiar ese dominio ¿no la tienen? Es válido cuestionarse, ¿cuál es la ideología de los dominantes (impulsores de la reforma de la reforma de la salud en el Perú) y la ideología de los que se oponen a ella, por ejemplo, quienes esgrimen el eslogan «la reforma que deforma»?

En esto del poder, también hay que tener en cuenta a Foucault:

[...] el poder no es algo limitado a los ejércitos y a los parlamentos: es, más bien, una red de fuerzas penetrantes e intangible que se enlaza con nuestros más ligeros gestos y nuestras manifestaciones más íntimas. Según esta teoría, limitar la idea del poder a sus más obvias manifestaciones políticas sería por sí misma una iniciativa ideológica, que ocultase la compleja difusión de sus actividades. Que concibamos el poder como algo que determina nuestras relaciones personales y actividades rutinarias es un beneficio político claro, como las feministas, por ejemplo, no han tardado en reconocer; pero entraña un problema para el significado de la ideología. Porque si no hay valores y creencias no ligadas estrechamente con el poder, el término ideología corre el peligro de extenderse hasta dejar de ser reconocible. Cualquier término que lo cubra pierde su filo y queda reducido a un sonido vacío. Para que un térmi- no tenga significado, debe ser posible especificar qué sería, en circunstancias particulares, lo opuesto a él -lo que no necesariamente significa especificar algo que fuese siempre y en todas partes lo contrario de él-. Si el poder, como el propio Todopoderoso, es omnipresente, la palabra ideología deja de distinguir cualquier cosa en particular y se convierte en algo carente de información -igual que si cualquier forma de comportamiento humano, incluida la tortura, puede pasar por muestra de compasión, la palabra compasión se reduce a un significado vacío (Eagleton 1997: 26).

Foucault, sobre la base de lo anterior, abandona sin más el concepto de ideología, reemplazándolo por el de "discurso", de mayor alcance. Pero esto lleva a renunciar a una distinción útil: la fuerza del término ideología reside en su capacidad para discriminar entre aquellas luchas del poder que son de alguna manera centrales a toda forma de vida social, y a aquellas que no lo son. Es el mismo peligro que cuando se dice: "todo es ideológico", o "todo es político". Es posible aceptar que el poder está en todas partes, pero es necesario distinguir entre tipos de poder más o menos necesarios (Eagleton 1997).

- El saber: Fue abordado en el apartado anterior con cierta amplitud, aunque aquí resulta interesante seguir con Foucault, que afirma lo siguiente:

[...] existe [...] una perpetua articulación del poder con el saber y del saber con el poder. No basta con decir que el poder tiene necesidad de éste o aquel descubrimiento, de esta o aquella forma de saber, sino que ejercer el poder crea objetos de saber; los hace surgir, acumula informaciones, las utiliza. No 
puede comprenderse nada del saber económico si no se sabe cómo se ejercía, en su cotidianeidad, el poder, y el poder económico. El ejercicio del poder crea perpetuamente saber e, inversamente, el saber conlleva efectos de poder" [...]. El humanismo moderno se equivoca, pues, al establecer esta división entre saber y poder. Ambos están integrados[...]. No es posible que el poder se ejerza sin el saber, es imposible que el saber no engendre poder" (Foucault 1999: 310).

Una definición que la mayoría utiliza cuando refiere el concepto ideología en las últimas décadas es algo semejante a la siguiente que acuñó Selinger:

Conjunto de ideas por las que los hombres proponen, explican y justifican fines y significados de una acción social organizada y específicamente de una acción política, al margen de si tal acción se propone preservar, enmendar, desplazar o construir un orden social dado (Selinger 1976: 11) ${ }^{14}$.

Entonces, la noción de ideología tiene un confuso estatus: para algunos las ideologías han muerto, y para otros están más vivas que nunca; hay quienes creen que es un concepto tan abarcador que pierde su significado y hay de los que lo utilizan puntualmente para acusar de algo negativo a sus rivales. Encabalgando lo encontrado, es posible metafóricamente hablar de nacimiento, vida y muerte de la ideología. Cuestión sobre la cual haremos algunas muy breves referencias.

Antes de hablar del fin de la ideología, de su muerte, es importante conocer de su nacimiento $y$, a grandes trancos, de su vida.
La ideología, como todos los niños, nació en París. La «ideología» definida como la ciencia de las ideas, según Destutt de Tracy, quien inventó el vocablo, era parte de la zoología o ciencia encargada de estudiar al animal humano:

Así, la noción de ideología surgió en condiciones estrictamente ideológicas: la ideología tenía que ver con una política racional, en contraste con la barbarie irracionalista del terror. Para que los hombres y mujeres se gobernasen verdaderamente a sí mismos, primero había que examinar pacientemente las leyes de su naturaleza. Se necesitaba, decía Tracy, un "Newton de la ciencia del pensamiento», puesto para el cual él era un claro candidato. Dado que toda la ciencia se basa en ideas, la ideología debía sustituir a la teología como reina suprema, garantizando su unidad. Reconstruiría la política, la economía y la ética desde la raíz, pasando desde los más simples procesos de la sensación hasta las más altas regiones del espíritu. Por ejemplo, la propiedad privada se basa en una distinción entre «tuyo» y «mío» que a su vez puede remontarse a una oposición perceptiva fundamental entre «tú» $\mathrm{y}$ «yo» (Eagleton 1997).

Con Napoleón, que inicialmente apoyó la ideología, y después, al devenir en autócrata, enfrentó lo que propugnaban los ideólogos: liberalismo político y republicanismo, tildándolo como " "charlatanes» y soñadores - una clase de hombres peligrosos que cuestionaba las raíces de la autoridad política y privaba brutalmente a hombres y mujeres de sus ficciones consoladoras- (Eagleton 1997: 92)". 
Napoleón atacó a los ideólogos justamente por ser enemigos de la ideología, pues ellos querían desmitificar las ilusiones sentimentales y la insensata religiosidad que él impulsaba para legitimar su dominio dictatorial.

Con la ideología pasó, entonces, como con muchos otros términos, un proceso por el cual de significar la ciencia o el estudio de un fenómeno se pasa a significar el fenómeno estudiado. Cercanamente esta mudanza de significado se ha podido apreciar en el Perú respecto a los términos "tramitología” y "opinología”, entre otros.

La ideología, entonces, pasó de ser la ciencia que estudia las ideas a significar los propios sistemas de ideas. Un ideólogo pasó de ser una persona que analiza las ideas a alguien que las defiende. La ideología que era ciencia devino en una estrategia profunda de reconstrucción social basada en un sistema de ideas, se transformó de ciencia a objeto de lucha ideológica.

Desde el enfrentamiento de Napoleón con DeTracy, la ideología queda peyorativamente señalada como "teórica» (en el sentido de lo opuesto a lo práctico), "abstracta», "radical», "difusa metafísica», "artificiosa», que teoriza sobre el conjunto y no sobre un problema concreto - de aquí la acusación de que los ideólogos siempre inician y concluyen sus análisis, según Roland Barthes, sosteniendo que "el sistema es el enemigo del "hombre»" Para Napoleón, en resumen, el excesivo racionalismo de los ideólogos tiene algo de irracional (Eagleton 1997).

Para desarrollar la ideología como ciencia, De Tracy escribió varios libros; uno de ellos dedicado a la ciencia de la economía, en el que postula que los intereses económicos eran los determinantes últimos de la vida social. Esto sería tomado por Marx como parte fundamental de su enfoque de la economía política capitalista.

Estudiando la economía, De Tracy encontró la radical «irracionalidad» de las motivaciones sociales en la sociedad de clases: los intereses egoístas, lo que le llevó a reconocer que la razón debe tener más en cuenta el sentimiento, el carácter y la experiencia.

Esto, a muy grandes rasgos, sobre el tiempo "perinatológico» de la ideología. $\mathrm{Y}$, continuando metafóricamente, como se sabe actualmente, los primeros tiempos de su vida determinan el devenir del ser.

Así pues, la aparición del concepto de ideología no es un mero capítulo de la historia de las ideas. Por el contrario, tiene una íntima relación con la lucha revolucionaria, y figura desde el principio como un arma de la lucha de clases. Entra en escena unida a las prácticas materiales de los aparatos ideológicos de Estado, y es en sí misma, en cuanto noción, un escenario de intereses ideológicos contrapuestos (Eagleton 1997: 100).

Desde entonces, mucho se ha producido teóricamente sobre la ideología, y se ha producido mucha ideología, sin que se haya variado lo que provoca: lucha ideológica.

Marx y Engels tratan sobre la ideología como parte de una concepción mayor que comprende la reificación y la alienación. Según Marx, en determinadas con-

15 Citado por Eagleton (1993). 
diciones sociales, las facultades, productos y procesos humanos escapan del control de los seres humanos y pasan a adoptar una existencia aparentemente autónoma. Estos fenómenos, alienados de este modo de sus agentes, pasan a ejercer un poder dominante sobre ellos, de forma que los agentes quedan sometidos a los productos de su propia actividad, como si estos fuesen fuerzas externas independientes, percibiéndose como cosas materiales, esto es reificándolas, y aceptando su existencia como inevitable.

Refieren Marx y Engels que la conciencia (como conjunto de ideas) es producto de las prácticas sociales ("el ser social determina la conciencia social") de los seres humanos, y está anclada en contradicciones reales que se dan en dichas prácticas, pero que mediante el proceso de alienación termina reificada, incluso convertida en un fetiche, como una cosa en sí misma. Esta ya es una concepción materialista de la ideología, a contramano de la concepción dominante hasta entonces: las ideas son la fuente de los cambios en la historia. En sus palabras:

En contraste directo con la filosofía alemana, que desciende de los cielos a la tierra, nosotros nos elevamos de la tierra al cielo. Es decir, no partimos de lo que los hombres dicen, imaginan, conciben ni de los hombres en cuanto seres narrados, pensados, imaginados, concebidos, para llegar a los hombres de carne y hueso. Partimos de los hombres reales y activos, y sobre la base de su proceso vital real demostramos el desarrollo de los reflejos ideológicos y de las repercusiones de este proceso vital... La vida no está determinada por la conciencia, sino la conciencia por la vida (Marx \& Engels 1974).
Algunos de los términos en la cita anterior (reflejos, ecos) podrían llevar a pensar que se está proponiendo un materialismo mecánico; sin embargo, como han reconocido sus autores en otros escritos, ellos conciben a las ideas como internas, propositivas o intencionales respecto a la vida práctica; a esta relación se refieren cuando utilizan el término "praxis" para remitir al carácter indisoluble entre acción y significación.

Los sistemas de creencias históricos particulares (las ideologías), desde esa postura, devienen en funcionales para el mantenimiento de las condiciones en las que las personas viven sus condiciones materiales en una sociedad dada, esto es, para legitimar tales relaciones. Más aún, una ideología, como conjunto solidario de ideas, está compuesta por creencias que no son verdaderas, que no tienen correspondencia con las prácticas que se dan en el orden social específico; de allí el término que acunó Engels para referirse a la ideología: falsa conciencia.

En consecuencia, dado que las ideas no son la fuente de la vida histórica, sino las contradicciones reales que hay en las prácticas sociales, las condiciones materiales de vida de un periodo histórico no se transforman con ideas que transforman las ideas prevalentes, sino mediante la abolición de las prácticas sociales desde las cuales se generan. Entonces, esta teoría materialista de la ideología resulta indesligable de una práctica revolucionaria.

En los escritos de Marx y Engels, el término "conciencia» significa «vida mental» o más específicamente sistemas de creencia históricas particulares (jurídicos, políticos, religiosos, artísticos, etc.). A esta última acepción refiere Marx con el término «su- 
perestructura», que él introdujo contraponiéndolo al concepto de «base» económica o práctica productiva (Marx 1989).

Globalmente, el término ideología se usa en dos sentidos: a) político: conjunto de creencias que se usan para legitimar la dominación de una clase social sobre otras, y b) epistemológico: naturaleza verdadera o falsa de dichas creencias, de donde se origina el concepto de falsa conciencia. Corresponden a los dos tipos de tradición que se presentó al inicio de este apartado.

¿Tienen estas concepciones de Marx y Engels alguna connotación en la salud pública? Un caso que puede ilustrar los conceptos que hasta aquí se han presentado $^{16}$ : en los últimos tiempos se ha desarrollado en el Perú un conflicto alrededor de lo que los cristianos llaman «la ideología de género». ¿Cómo ha actuado la gestión ministerial que se considera parte de la «tecnocracia» que gobierna al Perú? Enseguida algunos hechos, solo a manera de ilustración, esto es, para los efectos de esta presentación, sin emitir ninguna otra opinión respecto al resto del documento que se comentará.

Recién hace poco se aprobó y presentó el documento técnico Lineamientos de Politica de Promoción de la Salud en el Perú (Minsa, 2017), que en su marco teórico considera cuatro enfoques: 1 ) Territorialidad, 2) Equidad en salud, 3) Derechos humanos, 4) Interculturalidad. Antes tenía cinco enfoques, ¿cuál desapareció? El enfoque de género. El término género solo aparece dos veces en dicho documento: en la introducción, mencionando que es parte del Modelo de atención de salud basado en familia y comunidad (MAISBFC) y cuando resume los determinantes estructurales de la salud relacionados a la posición social.

Sin embargo, el enfoque de género es un tema central en las normas, modelos o propuestas que toma dicho documento como bases. Veamos algunos de ellos (solo respecto al punto tratado):

- Está vigente un documento técnico titulado Norma Técnica de Salud para la Transversalización de los Enfoques de Género e Interculturalidad en Salud, aprobado por resolución ministerial N. ${ }^{\circ}$ 638-2006/MINSA, en cuya presentación dice lo siguiente:

Entre las condiciones para garantizar el desarrollo humano es indispensable que las mujeres y hombres tengan acceso a los recursos, bienes y servicios para mejorar su salud y calidad de vida en igualdad de condiciones; en este marco la promoción y ejercicio de los derechos humanos, la Equidad de Género y la Interculturalidad en Salud desde el Ministerio de Salud es fundamental para que las personas y las instituciones conozcan y asuman sus derechos y responsabilidades en salud, participando activamente en la mejora de la situación de la salud individual y colectiva.

- En el documento de la Organización Panamericana de la Salud: Atención Primaria de Salud Renovada (OPS/OMS 2007), entre otras menciones se encuentra la siguiente:

Los Estados deben trabajar para alcanzar la meta del acceso universal a

16 Esto no implica una posición respecto al punto de conflicto (ideología de género) planteado. 
la atención de gran calidad para obtener el grado máximo de salud que se pueda lograr. Asimismo, deben determinar y eliminar las barreras al acceso institucionales, geográficas, étnicas, de género $^{17}$, culturales o económicas, y elaborar programas concretos para las poblaciones vulnerables.

- En el informe de la Comisión sobre los Determinantes Sociales de la Salud hay un capítulo entero sobre la necesidad de utilizar un enfoque de género -justo en la parte 4 que trata sobre el Poder y los recursos (OMS 2008).

- En la Declaración Política de Río sobre los Determinantes Sociales de la Salud (2011) dice "prestar una atención especial a los aspectos relacionados con el género»" ${ }^{18}$, así como al desarrollo en la primera in- fancia, en las políticas públicas y en los servicios sociales y de salud.

- Entre los Objetivos de Desarrollo Sostenible encontramos: «Objetivo 5: Lograr la igualdad entre los géneros y empoderar a todas las mujeres y las niñas».

Entonces, resulta difícil, por decirlo de alguna forma, entender las razones técnicas de por qué no se ha considerado el enfoque de género en los lineamientos de política que estamos comentando. Empero, entenderlo ideológicamente no es difícil.

La desaparición del enfoque de género entre los ejes transversales enunciados en el documento técnico Lineamientos de Política de Promoción de la Salud en el Perú, coincide con su "desaparición" en el gráfico correspondiente (Gráfico 1).

\section{GRÁFICO 1}

\section{Marco conceptual de los Determinantes Sociales de la Salud}

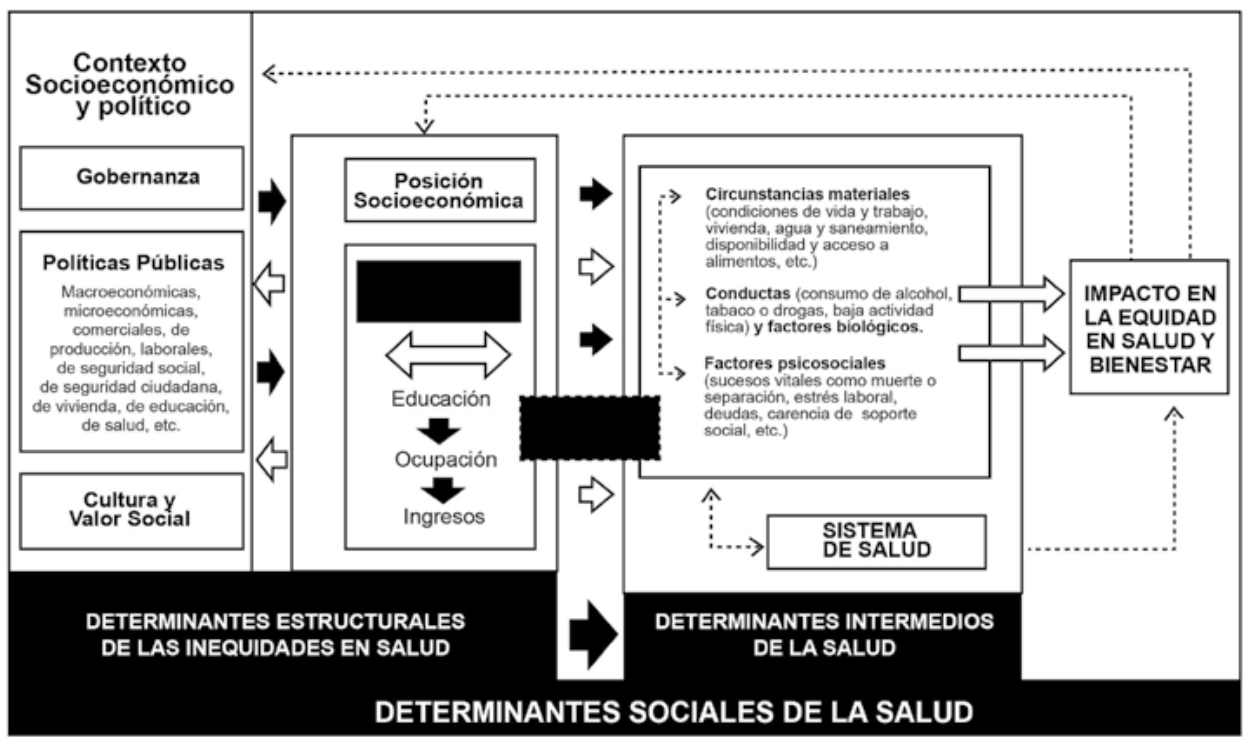

Fuente: Adaptado de Solar O., Irwin A. A Conceptual framework for action on the social determinants of health. Social Determinants of Health Discussion. Paper 2 (Policy and Practice). WHO 2010 
GRÁFICO 2

Final form of the CSDH conceptual framework

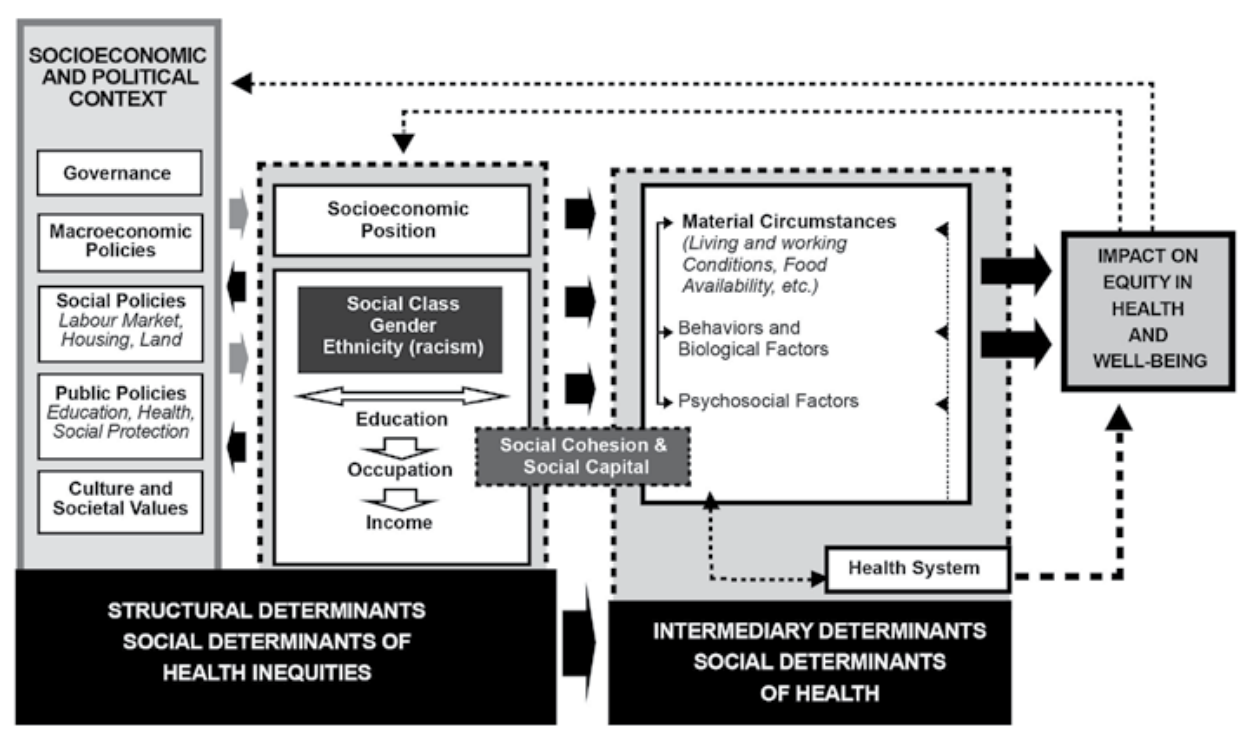

Fuente: Solar O., Irwin A. A conceptual framework for action on the social determinants of health. Social Determinants of Health Discussion Paper 2 (Policy and Practice), 2010.

En este gráfico se aprecian dos casilleros completamente oscuros. que imposibilitan leer sus contenidos. Si acudimos a la fuente anotada como el origen del gráfico, que corresponde al elaborado por Solar e Irwin que se muestra en el Gráfico 2, se puede leer: Social class, Gender, Ethnicity (racism) -traducido: Clase social, género y etnicidad (racismo) - en uno de ellos, y en el otro: Social cohesion \& Social capital (cohesión social y capital social).

En el Perú, de clase social no se habla hace mucho tiempo, ni se ha producido mayor teorización ni investigación empírica al respecto en el campo de la salud que no sea utilizando como indicadores los llamados «estratos socioeconómicos». El género resulta ahora una categoría sobre la que se da una álgida disputa ideológica y que, como se muestra, ha desaparecido de los Lineamientos... como uno de los enfoques eje de los estudios e intervenciones en salud. Lo étnico continúa en el discurso, sin embargo, en marzo de 2017 al modificarse el reglamento de organización y funciones del Ministerio de Salud (D. S. N. ${ }^{\circ} 008-2017-$ SA), la Dirección de Pueblos Indígenas fue desaparecida de la estructura orgánica del Ministerio de Salud, y solo hace poco, tras las protestas de diferentes organizaciones, incluyendo a la Defensoría del Pueblo, fue "incorporada" como parte de la Dirección General de Intervenciones Estratégicas en Salud Pública (D. S. N. ${ }^{\circ}$ 011-2017-SA).

Estas omisiones (o exclusiones) vistas en conjunto y contextualizadas aparecen como acciones políticas. La exclusión del enfoque de género no es un gazapo y tiene implicancias, y aceptando que unos lineamientos políticos son..., pues, políticos, entonces qué se puede entender cuando la primera política de Promoción de Sa- 
lud es «La salud como eje fundamental e integrado de todas las políticas públicas». Estando de acuerdo con el enunciado, habría que poner una nota que explicite para los despistados, "Salud, pero sin enfoque de género, como eje fundamental e integrado de todas las políticas".

Similar ejercicio podríamos realizar con el resto de las cuatro políticas y con sus documentos y modelos base, como el Modelo de Atención Integral de Salud basado en familia y comunidad, habría que alertar qué es el MAISBFC ${ }^{19}$, pero... sin el enfoque de género, o llamar a alcanzar los Objetivos de Desarrollo Sostenible, menos el objetivo 5. Hasta aquí con el ejemplo, cuya intención es solo ilustrar el punto de la relación ideología y salud pública, recordando a Althusser cuando dice que «todo pensamiento se despliega en los términos de una "problemática"20 inconsciente que de una manera silenciosa subyace en él» (Eagleton 1997: 177).

Entonces, en el documento técnico Lineamientos de políticas de promoción de la salud en el Perú, la "desaparición" del enfoque de género como uno de los ejes fundamentales y toda alusión al concepto de género puede -desde la connotación sociológica marxista de ideología- ser tomada por quienes defienden el enfoque de género como una clara muestra de falsa conciencia: conjunto de ideas para legitimar una situación de dominación en la sociedad de una clase sobre otras, la reificación del género para contraponerla a una condición biológica: el sexo, y, en otros casos, su invisibilización, fórmula ideológica, esta última, semejante a la descrita por Foucault respecto a la locura en la Época Clásica ${ }^{21}$ o como la invisibilización de la figura de Trotsky en fotografías del alto mando bolchevique. Igualmente, quienes son contrarios al enfoque de género pueden recusarlo de ser una ideología, en su connotación marxista que remite a la cognición, de ser también una falsa conciencia. En ambos casos, debe partirse de aceptar que se trata de la lucha de una ideología contra otra, aunque lo común como es lo usual desde la lucha entre $\mathrm{Na}$ poleón y De Tracy- es que una posición presente a la otra como «ideología» (en el sentido peyorativo) y busque autolegitimarse en alguna forma "no ideológica».

De lo presentado se puede concluir que los tres «desaparecidos» determinantes estructurales (clase social, género y etnicidad) no constituyen realmente una prioridad en el enfoque «técnico» de los gobernantes actuales, lo cual, indica sus posiciones ideológicas y políticas derivadas. Eliminar la cuestión de género en las políticas de salud no es solo un cambio en el sentido foucaultiano general de «discurso", sino en el sentido específico del concepto de ideología, ya que atañe a un aspecto central de la vida social.

No es intención de esta presentación hacer una revisión sobre el itinerario del concepto de ideología, sobre el cual existe una excelente obra de Terry Eagleton: Ideología. Una introducción. Sin embargo, es importante levantar algunos otros temas relativos al desarrollo de la ideología como concepto, porque ha ido variando desde su aparición,

19 Documento técnico aprobado mediante RM 4645-2011/MINSA.

20 Para Althusser, una problemática es algo parecido a lo que Foucault llama episteme: una organización particular de categorías que constituye los límites de los que podemos expresar y concebir en un particular momento histórico.

$21 \mathrm{Al}$ respecto, ver los estudios de Foucault, los tres tomos de Historia de la Locura en la época clásica. 
en algunos aspectos radicalmente, en este ejercicio de reflexionar sobre algunos aspectos de la salud pública en el Perú.

Lenin cambia el sentido peyorativo del término ideología, cuando introduce la idea de la "ideología socialista", como un conjunto de creencias que junta e inspira a un grupo o clase social específico que buscan un orden social deseable. Esta definición se contrapone directamente con el concepto de falsa conciencia como creación de la clase dominante para mantener una situación establecida. Para Lenin, los ideólogos deben ser visto como analistas científicos de las leyes fundamentales de la sociedad, de cuyo estudio resulta la teoría del materialismo histórico, constituyéndose ellos a su vez en los portadores de la ideología socialista.

Antonio Gramsci también rechaza la connotación negativa de la ideología, comprendiéndola junto con la cultura como una práctica social auténtica y no necesariamente articulada al funcionamiento institucional. Para Gramsci, la categoría central no es ideología, sino hegemonía, término por el cual refiere al "modo en que el poder gobernante se gana el consentimiento de aquellos que sojuzga". La diferencia sustantiva estriba en que las ideologías pueden imponerse por la fuerza, más aún:

$\{\ldots\}$ hegemonía es también una categoría más amplia que ideología: incluye la ideología, pero no es reducible a ésta. Un grupo o clase dominante puede justificar su poder por medios ideológicos; pero también puede hacerlo, pongamos por caso, cambiando el sistema de impuestos de un modo favorable a aquellos grupos de los que necesita apoyo, o creando un estrato de trabajadores relativamente opulentos $\mathrm{y}$, por tanto, más o menos acomodaticios desde el punto de vista político. La hegemonía también puede tomar formas más políticas que económicas: el sistema parlamentario de las democracias occidentales es un factor crucial en este dominio, ya que alienta la ilusión de un autogobierno del pueblo [...].

[...] Otra fuente de hegemonía política es la supuesta neutralidad del Estado burgués. En realidad, ésta no es una simple ilusión ideológica. [...] En el capitalismo, la vida económica no está sujeta a un control político tan constante..., la sola necesidad de sobrevivencia, es lo que hace que hombres y mujeres se pongan en marcha, al margen de cualquier tipo de obligaciones políticas, sanciones religiosas o responsabilidades habituales. Es como si en este sistema de vida la economía funcionara «por si sola», y el Estado político se mantuviera en la retaguardia, sosteniendo las estructuras generales en las que se da esta actividad económica. [...] La hegemonía, pues, no sólo es una forma de ideología eficaz, sino que podemos distinguir entre sus aspectos ideológicos, culturales, políticos y económicos. La ideología se refiere específicamente al modo en que se libran las luchas de poder en el nivel determinante $y$, aunque esta determinación está implicada en todos los procesos hegemónicos, no siempre es el nivel dominante por el que se mantiene el gobierno (Eagleton 1997).

Muchos otros autores han contribuido a la gran temática científica que tiene a la ideología como categoría central, mu-

22 Ya se ha referido que se puede encontrar una excelente introducción a esta temática en Eagleton (1998). 
cho se ha desplegado desde que De Tracy la empezara como el estudio de las ideas ${ }^{22}$.

Ya hacia el final de este texto, es importante mencionar nuevamente a Bourdieu, esta vez respecto a su trabajó sobre los mecanismos por los que la ideología incide en la vida cotidiana, las "microestructuras" de la ideología, entre las cuales se encuentran los habitus sobre los cuales se trató antes y la doxa, término que remite a un tipo de orden social estable y ligado a la tradición en el que se naturaliza totalmente el poder, considerándolo incuestionable, de modo que no puede siquiera imaginarse ninguna ordenación social diferente de la actual.

La concepción hegemónica, según definición de Gramsci, que incluye a la ideología, la política, la economía, el saber, la cultura, de la salud pública en Perú ¿actúa cual doxa? ¿resulta incuestionable? ¿Se requiere que los intelectuales se asuman como tales en el sentido leninista: analistas científicos de la realidad sanitaria y portadores de una ideología sanitaria diferente que no reforme, sino que revolucione la salud pública peruana, que, parafraseando a Foucault: dejen de ser "profetas universales" y se conviertan en "especialistas"?

Se puede afirmar, con carácter de hipótesis y con una declarada intensión de provocar reflexión y discusión: en el Perú, los intelectuales especialistas en la problemática de salud pública son escasos, y, aunque tienen importantes intuiciones $y$ avances sobre un orden sanitario diferente, no han llegado a articularse como una masa crítica capaz de desplegar manifestaciones de poder que pongan, aunque sea lejanamente, «en jaque» al modelo sanitario hegemónico.Estos intelectua- les sanitarios pueden ser tomados como intelectuales orgánicos -según definición de Gramsci-, mas queda en pie la cuestión de si el cambio de modelo sanitario puede producirse solo en el campo de la salud -sin que se mude mayormente los otros campos sociales y los productivos-, y si la respuesta fuera positiva ¿qué es lo que haría posible un proceso como, por ejemplo, el sistema de salud de Inglaterra, Canadá, Costa Rica, Brasil?, ¿una fuerte sociedad civil, las instituciones de variable naturaleza que están entre el Estado y la economía, según Gramsci?, ¿cómo esto sería posible cuando las instituciones de la «sociedad civil»-escuela, familia, Iglesia, medios de comunicación y otras- desempeñan como papeles centrales la reproducción y control social?, ¿no será acaso que la gran mayoría de las instituciones de la sociedad civil sí comparten, en la práctica, la concepción hegemónica (que actúa cual doxa) en el campo de la salud, en general, y respecto a la salud pública, en particular?, ¿será la debilidad de la sociedad civil lo que no permite que el descontento con el «sistema» de salud de Perú y los avances de los intelectuales especialistas en salud pública logren al menos colocar la salud como uno de los puntos centrales en la agenda política peruana?

También, partiendo del convencimiento de que para hacer salud pública es necesario contar con una dotación de habitus específicos, los que pueden clasificarse de acuerdo a la taxonomía que propuso Althusser como "ideologías en estado práctico" (que contrapone a las "ideologías teóricas"), resulta pertinente preguntarnos ¿Qué ideología práctica tienen los «gestores» de salud en el Perú cuando frente al problema de la contaminación de los pobladores de Cerro 
de Pasco (tomado solo como el caso de «los niños del plomo» en los medios de comunicación) obvian la fuente de contaminación? Eso ni siquiera es tener presente el modelo epidemiológico clásico, menos aún el tan difundido modelo de los determinantes sociales de la salud (OMS 2008), ni -más lejos aún- el enfoque de la determinación de la vida y la salud (Breilh 2010).

Muchas más preguntas requieren respuestas y acciones en consecuencia, pero quizás no las hay; porque aún no se ha vuelto costumbre el preguntarse sobre el poder, el saber y la ideología en el campo de la salud pública. Por ejemplo, siguiendo con las interrogantes sobre las relaciones entre la salud pública y las ideologías: jes posible una salud pública sin ideologías?, ¿basta un conjunto de habitus técnicos relacionados a la acción y al conocimiento en el campo de la salud pública? Ciertamente, entre los capitales específicos del campo de la salud pública está el capital técnico, que aparece como el capital simbólico, el que legitima a quien detenta el poder. Incluso, se impulsa mucho la idea de que, por ejemplo, "un ministro es un buen técnico", y la ilusión de que estamos siendo gobernados por técnicos: "tecnocracia», le dicen, y se alienta en el imaginario popular el concepto de que existe un campo tecnológico (sociotecnológico) que es un espacio neutro de relaciones individuales e interinstitucionales.

A modo de digresión, llama la atención la demanda general entre los diferentes grupos para que los gobernantes sean buenos técnicos. Se ha escuchado a presidentes de la República presumir de la excelencia técnica de sus ministros, incluso catalogarlos como «ministros de lujo», pero nunca de sus bondades científicas, rara vez de sus fortalezas políticas y nunca de sus bondades éticas.

Sobre la ciencia y la política es importante tener en cuenta lo siguiente:

[...] en el pensamiento de Max Weber, las relaciones entre ciencia y política no se caracterizan solamente, como siempre se dice, por la distinción necesaria. La ciencia que él concibe es aquella susceptible de servir al hombre de acción, del mismo modo que la actitud de éste difiere en su fin, pero no en su estructura, de la del hombre de ciencia. El hombre de acción es el que, en una coyuntura singular y úni$c a$, elige en función de sus valores e introduce en la red del determinismo un hecho nuevo. Las consecuencias de la decisión tomada no son rigurosamente previsibles, en la medida en que la coyuntura es única. Sólo hay previsión científica en las sucesiones de acontecimientos que pueden repetirse o, dicho en otros términos, sólo hay previsión científica respecto de las relaciones derivadas de lo concreto y elevadas a un cierto nivel de generalidad. No es menos cierto, sin embargo, que la decisión razonable exige que se aplique a la coyuntura el conjunto de conocimientos abstractos de que se dispone, no para eliminar el elemento de imprevisible singularidad, sino para reducirlo y aislarlo. Una ciencia que analice las relaciones de causa y efecto, como Max Weber deseaba para la teoría, es así también la misma que responde a las necesidades del hombre de acción (Aron 2007: 10-11).

Entonces, si lo que se busca es un buen técnico, -siguiendo con este ejercicio intelectual, no como propuesta- lo técnico sería que se ocupe los altos puestos de dirección de la salud pública -nos referi- 
mos aquí a los lugares más altos en la jerarquía burocrática del aparato estatal en salud- mediante un proceso de selección técnico. Pero ello no ocurrirá, ya que, sea consciente o inconscientemente, quienes eligen, designan, encargan, delegan, saben que tales cargos son políticos, son los puestos desde donde se diseñan, deciden, ponen en ejecución y evalúan las políticas (aunque se les llame lineamientos de política), y que los políticos que deben ocupar dichos cargos son los que concuerden ideológicamente con el designante ${ }^{23}$.

Hasta aquí la digresión sobre el científico, el político y el técnico, para decir algo final sobre la ideología.

Tras un salto, en las últimas décadas no se han dado muchos aportes al tema de la ideología, excepto por Lyotard y su «fin de los grandes relatos» $\mathrm{o}$ "la condición postmoderna», y Fukuyama y el "fin de la historia». Ampliar y ahondar al respecto escapa a los alcances de la actual presentación; sin embargo, un par de comentarios más.

Es interesante notar hoy con claridad que el declarado "fin de los grandes relatos» del filósofo Lyotard estaba especialmente dirigido al marxismo; aunque después se dedicó a trabajar sobre los viajes intergalácticos, la entropía cósmica y el éxodo masivo de la tierra tras la extinción del sol dentro de cuatro mil millones de año (Eagleton 2005: 62). Sobre el fin de las ideologías como parte del "fin de la historia», solo basta dar una mirada a los grandes $y$, muchos de ellos trágicos, acontecimientos de las últimas décadas para saber que movimientos ideológicos de todo tipo están sumamente vivos (y varios de ellos matando), en todo el mundo y produciendo, justamente, grandes acontecimientos sociales.

\section{CODA}

En la mañana en que tuvo lugar la disertación que ha servido de base para elaborar este texto, al leer los diarios, una noticia particularmente llamó mi atención: 12 de julio, Conmemoración de la Toma de la Bastilla, Fiesta Nacional de Francia. Pensé: las cosas que sabemos, pero no sabemos que sabemos.

Siempre pensando en París, dejo como hilo suelto de una madeja para seguir reflexionando una cita de Bourdieu:

[...] pienso en efecto que no se puede combatir eficazmente la tecnocracia, nacional o internacional, si no es enfrentándola en su terreno privilegiado, el de la ciencia, principalmente económica, y, oponiendo al conocimiento abstracto y mutilado del cual ella se vale, un conocimiento más respetuoso de los hombres y de las realidades a las cuales ellos se ven confrontados (Bourdieu 1995).

$\mathrm{Y}$, también, anoto enseguida la parte final del poema Los Nueve Monstruos, de César Vallejo, tantas veces usado para describir la situación de salud de la población peruana. Releámosla desde la situación actual:

¡Cómo, hermanos humanos, no deciros que ya no puedo y ya no puedo con tanto cajón, tanto minuto, tanta lagartija y tanta inversión, tanto lejos y tanta sed de sed! Señor Ministro de Salud: ¿qué hacer? ¡Ah! desgraciadamente, hombres humanos,

hay, hermanos, muchisimo que hacer.

23 Los casos calificados como excepciones tienen un carácter discutible. 


\section{BIBLIOGRAFÍA}

Aron, R. (2007). Introducción. En M. Weber, El politico y el cientifico. Madrid: Alianza Editorial.

Colegio Médico del Perú. Consulta: 17 de agosto de 2017. Disponible en: $<$ http://cmp.org.pe/huelga-medica-collar-de-lagrimas/ $>$.

Congreso de la República-Peru (2017). Constitución Política del Perú. Lima: Editorial Congreso de la República.

Bateson, G., \& Bateson, M. C. (1987). Donde los ángeles temen pisar. Barcelona: Gedisa.

Bourdieu, P. (14 de diciembre de 1995). Combatir a la tecnocracia en su propio terreno. Liberación.

Bourdieu, P. (2002). Campo de poder, campo intelectual. Itinerario de un concepto. Tucumán: Montressor.

Bourdieu, P. (2007). El sentido práctico. Buenos Aires: Siglo XXI.

Breilh, J. (2009). Spondylus. Consulta: 19 de agostso 2017. Disponible en: <http:// www.uasb.edu.ec/web/spondylus/ contenido?jaime-breilh-34la-industria-porcicola-es-el-origen-del-gripe-a-h1n1-34\&s=ENTREVISTA $>$.

Breilh, J. (2010). Las tres "S" de la determinación de la vida. 10 tesis hacia una visión critica de la determinación social de la vida y la salud. En R. Passos Nogueira, Determinacao social da saúde e reforma sanitária. Rio de Janeiro: CEBES.

Bunge, M. (2009). Filosofía Politica. Solidaridad, cooperación y Democracia Integral. Barcelona: Gedisa.

Eagleton, T. (1997). Ideología. Una introducción. Barcelona: Paidós.
Eagleton, T. (2005). Después de la teoría. Barcelona: Debate.

Elias, N. (1997). Sobre el tiempo. México: FCE.

Foucault, M. (1976). Vigilar y Castigar. El nacimiento de la prisión. Buenos Aires: Siglo XXI.

Foucault, M. (1999). Entrevista sobre la prisión: El libro y su método. En $\mathrm{M}$. Foucault, Estrategias de poder. Barcelona: Paidós.

Frenk, J. (1991). La nueva salud pública. Cuernavaca: OPS.

Frenk, J. \& Gómez-Dantés, O. (2007). La globalización y la nueva salud pública. Salud Pública. Mex, 49(2), 156-163.

Gehlen, A. (1993). Antropología filosófica. Del encuentro y descubrimiento del hombre por sí mismo. Barcelona: Paidós.

Henao-Kaffure, L. (julio-diciembre de 2010). El concepto de pandemia: debate e implicaciones a propósito de la pandemia de influenza de 2009. Revista Gerencia y Politicas de Salud, 9(19), 53-68.

Johnson, S. (2003). Sistemas emergentes. $O$ qué tienen en común hormigas, neuronas, ciiudades y software. México: Turner-FCE.

La República (2017) [edición digital]. Consulta: 16 de agosto 2017. Disponible en: <http://larepublica.pe/ politica/889387-chacon-sobre-indulto-fujimori-perez-tello-tiene-un-sesgo-ideologico>.

Marx, C. (1989). Contribución a la crítica de la economía política. Moscú: Progreso.

Marx, C. \& Engels, F. (1974). La ideología alemana. Barcelona: Grijalbo.

Maturana, H. \& Varela, F. (1994). De Máquinas y Seres Vivos. Autopoiesis: la 
organización de lo vivo. Santiago de Chile: Editorial Universitaria S.A. Lumen.

Maturana, H. (1995) La ciencia y la vida cotidiana: la ontología de las explicaciones científicas. En Watzlawick, P. \& Krieg, P. El Ojo del Observador. Contribuciones al constructivismo. Barcelona: Gedisa.

MINSA. (19 de mayo de 2017). Resoluciòn ministerial No 366-2017/MINSA. Aprobación del Documento Técnico "Lineamientos de Politica de Promoción de la Salud en el Perú".

Morin, E. (1977). El método I. La naturaleza de la naturaleza (Primera ed.). Madrid: cátedra.

Morin, E. (1998). El Método IV. Las Ideas. Madrid: Cátedra.

Morin, E. (2002). La epistemología de la complejidad. Gazeta de Antropología, 20. (P. Gómez, Ed.) Recuperado el 16 de marzo de 2017, de Universidad de Granada: http://hdl.handle. net/10481/7253

Morin, E. (2003). El Método V: La humanidad de la humanidad. Madrid: Cátedra.

OPS/OMS. (2002). La Salud Pública en las Américas. Nuevos conceptos, análisis del desempeño y bases para la acción. Washington, D.C.: OPS.

OPS/OMS. (2007). La Renovación de la Atención Primaria de Salud en las Américas. Washington, D.C.: OPS.

OMS. (2008). Comisión Sobre los Determinantes Sociales de la Salud., Informe final. Ginebra: OMS.
Pascal, B. (2004). Pensamientos. Madrid: Alianza Editorial.

Popper, K. (1978). The Three Worlds. The Tanner Lecture on Human Values. Michigan: University of Michigan. Primer Congreso Mundial de Transdisciplinariedad. (Noviembre de 1994). Carta de la Transdisicplinariedad. Convento de Arrábida.

Popper, K., \& Lorenz, K. (1985). El porvenir está abierto. Conversación de Altenberg y textos del simposio sobre Popper celebrado en Viena. (o. e. r1.2, Ed., \& T. d. Loayza, Trad. Real Academia Española. (2014). Diccionario de la lengua española (Vigésimo tercera ed.). Madrid, Espańa: RAE.

Savater, F. (2003). El Valor de Elegir. Barcelona: Ariel.

Selinger, M. (1976). Ideology and Politics. Londres.

Tribunal Constitucional Peruano. (2002). Sentencia sobre el caso Challapalca.

Tribunal Constitucional Peruano. (2003). Sentencia del Caso Azanca Meza.

Varela, F. (2005). Conocer. Las ciencias cognitivas: tendencias y perspectivas. Cartografia de las ideas actuales. Barcelona: Gedisa.

Von Foerster, H. (1998). Por una nueva epistemología. Metapolítica, 2(8), 629-641.

Watzlawick, P. (1979). ¿Es real la realidad? Confusión, desinformación, comunicación. Barcelona: Herder.

Weber, M. (1996). Economia y sociedad. México: FCE. 